University Department of General Practice in Edinburgh during November 2008).

\section{REFERENCES}

1. Collings JS. General Practice in England today: A Reconnaissance. Lancet 1950; i: 55-85.

2. Loudon I, Horder J, Webster C. Developments in other countries. In: General Practice under the National Health Service 1948-1997. London: OUP, 1998: 256.

3. McWhinney IR. General practice as an academic discipline. Lancet 1966; i: 419-23.

4. Richardson IM. The value of a university department of general practice. $B M J 1975$; iv: 740-742.

5. Pereira Gray DJ. Forty years on: the story of the first forty years of the Royal College of General Practitioners. London: RCGP, 1992.

6. Howie JGR, Hannay DR, Stevenson JSK. The Mackenzie Report. General practice in the medical schools of the United Kingdom - 1986. Edinburgh: University of Edinburgh, 1986

7. Royal College of General Practitioners. The future general practitioner: Learning and Teaching. London: RCGP, 1972.

8. Howie JGR, Metcalfe DHH, Walker JH. The state of general practice - not all for the better. BMJ 2008: 336:1310.

DOI: 10.3399/bjgp10X515205

\title{
The Research Paper of the Year Award 2009
}

Earlier diagnosis of cancer is a compelling objective for GPs and this year's RCGP Paper of the Year makes a significant contribution in the case of ovarian cancer. ${ }^{1}$ The Bristol team led by Willie Hamilton undertook a case-control study using GP records in 39 Devon practices as part of the prevention and early diagnosis programme of the School for Primary Care Research. ${ }^{2}$ Their project identified seven symptoms which could help clinicians to diagnose ovarian cancer at an earlier stage than we achieve at present: abdominal distension; postmenopausal bleeding; loss of appetite; increased urinary frequency abdominal pain; rectal bleeding; and abdominal bloating. The study concluded:

\section{'Women with ovarian cancer usually have symptoms and report them to primary care, sometimes months before diagnosis. This study provides an evidence base for selection of patients for investigation, both for clinicians and for developers of guidelines'.}

As Frede Olesen pointed out in his contribution to the UK Academy of Medical Science report last year, that evidence base is needed worldwide and British general practice could and should be contributing more to providing it. ${ }^{3}$

The UK has developed an excellent system of patient care with near universal electronic records and research networks which enable practices and academics to address important issues. ${ }^{4}$ As the RCGP and academic groups work more closely together we are also now developing the ability for primary care clinicians to influence the agenda being pursued by research teams. Readers of the BJGP and College members attending the RCGP Annual Primary Care Conference will notice that the studies being undertaken are of increasing clinical relevance. They should also take the opportunity to influence the research agenda provided by the improved communication channels for example through the Clinical Innovation and Research Centre (CIRC). ${ }^{5}$

The Research Paper of the Year Award is one strand of the work undertaken by CIRC. The award has been presented by the RCGP each year since 1996 to raise awareness of high quality studies taking place within general practice and to encourage more GPs to become actively involved in research. The findings from the 2009 award winning paper were widely reported in the mass media and have been rapidly picked up by several ovarian cancer awareness charities, including Ovarian Cancer Action, which highlighted the early indicators in its Remember the Symptoms campaign in March 2010. ${ }^{6}$ We also hope that the winning paper's messages are being integrated into undergraduate and postgraduate curricula to influence the care we deliver.

\section{Frank Sullivan}

\section{REFERENCES}

1. Hamilton W, Peters TJ, Bankhead C, Sharp D. Risk of ovarian cancer in women with symptoms in primary care: population based case-control study. BMJ 2009; 339: b2998.

2. NHS National Institute for health Research. School for Primary Care Research. Programme 1. Prevention and early diagnosis.

http://www.nspcr.ac.uk/ThemeDetails.cfm?ID=1 (accessed 12 Jul 2010).

3. The Academy of Medical Sciences. Research in general practice: bringing innovation into patient

http://www.acmedsci.ac.uk/index.php?pid=44\&evid= 102 (accessed 12 Jul 2010).

4. Sullivan F, Butler C, Cupples M, Kinmonth AL. Primary care research networks in the United Kingdom. BMJ 2007; 334:1093-4.

5. RCGP. Clinical Innovation and Research Centre (CIRC).

http://www.rcgp.org.uk/clinical_and_research/circ.as px (accessed 12 Jul 2010).

6. Ovarian Cancer Action. What every woman should know about ovarian cancer.

http://www.ovarian.org.uk/ovariancancer/whatyoush ouldknow.asp (accessed 12 Jul 2010).

DOI: 10.3399/bjgp10X515214 